\title{
Numerical analysis of double inlet two-stage inertance pulse tube cryocooler
}

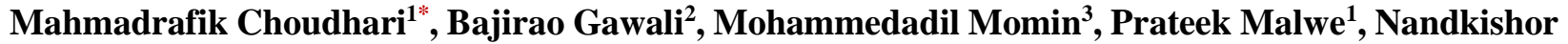 \\ Deshmukh $^{1}$ and Rustam Dhalait ${ }^{1}$ \\ Research Scholar, Walchand College of Engineering, Sangli-416415, India ${ }^{1}$ \\ Professor, Walchand College of Engineering, Sangli-416415, India ${ }^{2}$ \\ M.Tech Scholar, Walchand College of Engineering, Sangli-416415, India ${ }^{3}$
}

Received: 08-May-2021; Revised: 25-June-2021; Accepted: 27-June-2021

(C)2021 Mahmadrafik Choudhari et al. This is an open access article distributed under the Creative Commons Attribution (CC BY) License, which permits unrestricted use, distribution, and reproduction in any medium, provided the original work is properly cited.

\begin{abstract}
Stirling-type Pulse Tube Cryocoolers (PTC) are designed to meet present and upcoming commercial requirements and needs with durability and low vibrations. Multistaging in Stirling type PTC is one of the major developments reported in recent times for low-temperature achievement, due to improved performance over a period of time. The current study aims to define the methodology for numerical assessment of Double Inlet Two-Stage Pulse Tube Cryocooler (DITSPTC) to achieve cryogenic temperature of $20 \mathrm{~K}$. This paper performs Computational Fluid Dynamics (CFD) simulation of PTC for defining the methodology using the CFD software package and then the same methodology is extended for the analysis of DITSPTC. The system simulations are performed with frequency of $70 \mathrm{~Hz}$ and average pressure of 20 bar. The minimum temperatures obtained from simulations are $95 \mathrm{~K}$ and $20 \mathrm{~K}$ at the first and second stage respectively.
\end{abstract}

\section{Keywords}

Pulse tube cryocooler, CFD, Cryogenic temperature, Multistaging, Double inlet valve.

\section{Introduction}

The basic Pulse Tube Cryocoolers (PTC) was invented by Gifford and Longsworth [1]. A compressor is used to drive this system which does pressurization and depressurization of working gas to obtain the required effect in the system. Continuous analysis and subsequent enhancement in the performance of PTC has done in the last few decades. Mikulin et al. [2] introduced the orifice type PTC.

The addition of an orifice valve results in Cold End Heat Exchanger (CHX) temperature of $105 \mathrm{~K}$ using air as the working fluid. Based on phase shift, design variations were proposed as double inlet Orifice Pulse Tube Cryocooler (OPTC) [3] and Inertance Tube Pulse Tube Cryocooler (IPTC) [4]. They proposed that the performance of the basic PTC can be enhanced by adding a phase-shifting mechanism as shown in Figure 1. The setting of a double inlet valve governs the performance of the cryocooler to a great extent. The distribution of the total gas from the compressor into the stages is crucial as it mainly depends on the area available through the double inlet valve. Accordingly, the mass flow rate through the valve is the governing factor.

*Author for correspondence

766
Hu et al. [5] done numerical and experimental studies of DIPTC and IPTC. They determined that optimal phase shift cannot be obtained by the use of an inertance tube only for low cooling power, but can provide an optimum phase shift for PTCs with high cooling power. Double inlet valve incorporated to obtain optimal phase shift in case of low cooling power PTC. Roy and Kundu [6] done the thermodynamic analysis of basic PTC, OPTC, and DIPTC and shown that the DIPTC gives better cooling performance than basic PTC, OPTC.

Multistaging in Stirling type PTC is one of the major developments reported in recent times, due to its simplicity of operation and improved performance over a period of time. Multistaging in cryocoolers is required to attain much lower temperatures [7]. PTCs are thermally coupled in series to form the multistage PTC. The first stage is employed to precool the second stage. Matrix with different sizes and materials can be employed depending on the operating temperature range, resulting in improved efficiency and lower cost. Cryocoolers are connected in series to reach the lower temperature region. One stage is used to precool the next stage. Single-stage Stirling type PTC can reach down to a temperature of 40-50 K, while temperatures around $20 \mathrm{~K}$ could be achieved by two-stage PTC. For 
below $10 \mathrm{~K}$, three-stage PTC is used [8]. The very first two-stage Stirling type PTC is reported in the literature by Yang et al. [9]. The developed unit has coaxial geometry for both stages. Tendolkar et al. [10] done experimental investigations on an integralconfiguration Stirling-type Two-Stage Pulse Tube Cryocooler (TSPTC). A double inlet valve is incorporated to the second stage with an inertance tube for the enhancement in the performance of the system. Dietrich and Thummes [11] developed a TSPTC for a cooling load of $12.9 \mathrm{~W}$ at $25 \mathrm{~K}$. The specialty of this system is the use of cold head instead of the cold end heat exchanger in the first stage as no cooling is required at intermediate temperature. $\mathrm{Wu}$ et al. [12] achieved $15 \mathrm{~K}$ with a cooling load of $0.3 \mathrm{~W}$.

Recent advancements in the multistaging of IPTC are the addition of step displacer as a phase shifter [1316], Stirling/Pulse Tube Hybrid Cryocooler (SPC) [17], cryogenic phase-shifting mechanism [18], and cascading of cryocoolers [19]. Pang et al. [13, 14] added step displacer in two-stage PTC to enhance the performance. Integral structure type step displacer improved efficiency by $5.42 \%$. Step displacer implements two functions, one is to distribute work between two stages and the second is to control phase shift. In the second stage of step displacer Two-Stage Inertance Pulse Tube Cryocooler (TSIPTC), the cyclic steady temperature of $16.9 \mathrm{~K}$ is attained at CHX experimentally $[15,16]$. Raytheon Company developed an innovative SPC in 1999. SPC is made with a combination of Stirling cryocooler and PTC in the first and second stage respectively. SPC has the collective advantage of high efficiency and reliability from Stirling cryocooler and PTC respectively. That's the reason why SPC is suitable for space application. Liu et al. [17] developed SPC with cooling capacity of $1.16 \mathrm{~W}$ at $35 \mathrm{~K}$ and $7.25 \mathrm{~W}$ at $85 \mathrm{~K}$. Dang et al. [18] used a cryogenic phase-shifting approach instead of an external precooling approach to avoid complexity in multistaging. In the case of the three-stage PTC, inertance tube and reservoir of the third stage kept in cryogenic environment instead of ambient, which improves the performance of the system. Jeong and Jin [19] compared two-stage cryocooler and cascade cryocooler on the thermal performance basis and it is observed that cascading performs better when the temperature ratio is large.

For the design and optimization of PTC, there are different models accessible in the literature with certain benefits and some limitations. The experimental assessment of PTC is tremendously demanding and expensive, while analytical is a timerequiring assessment method. Most of the researchers developed different numerical models for analysis due to the accurate prediction of results. Isothermal model [20-22], adiabatic model [10, 23], energy equation model [24], and Computational Fluid Dynamics (CFD) model [25-27]. The isothermal model and adiabatic model are extensively used due to their simplicity. These models can give broad clarification by considering the real process occurring in the system to some extent. At lower cold end temperatures, it is found that the energy equation model can anticipate the cooling power performance of the PTC system sensibly well. CFD model can give detailed clarification about the real process occurring in the system and it predicts much more accurate results. Researchers have done CFD analysis of PTC for different geometrical and operational parameters with $2 \mathrm{D}$ axisymmetric $[25,26]$ and $3 \mathrm{D}$ plane-symmetric models [27, 28]. For optimization of PTC, CFD models [29] and various artificial intelligence methods like ANN, PSO-ANN, and ANFIS method are used to attain maximum refrigeration and Coefficient of Performance (COP) by giving an optimum range of inputs [30-32]. Panda et al. [32] revealed that refrigerating capacity and COP increased by $10.8 \%$ and $0.76 \%$ respectively.

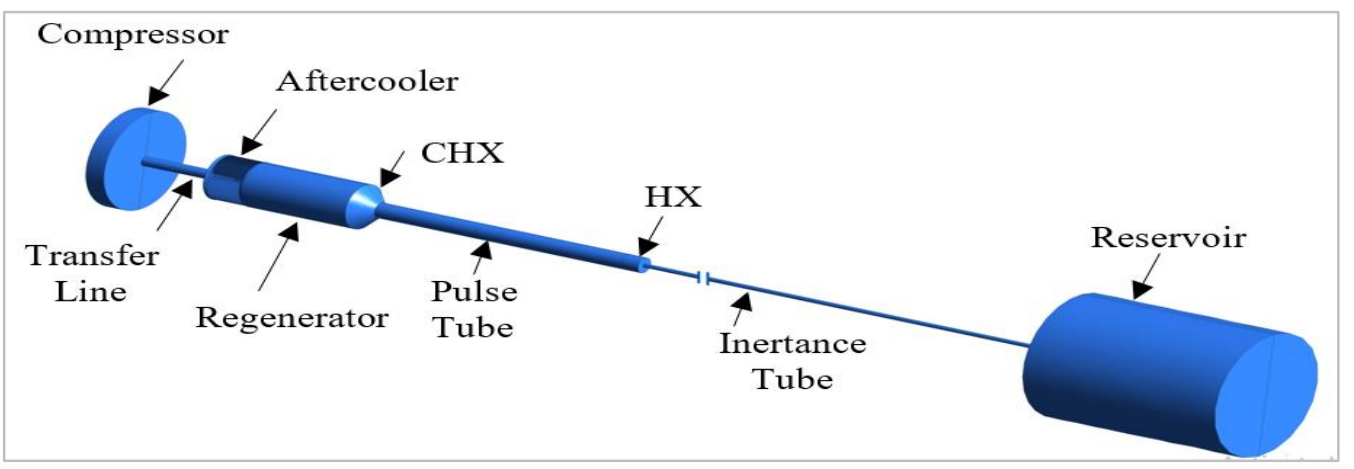

Figure 1 Inertance pulse tube cryocooler system 
Exhaustive literature is available about single-stage configurations. However, very scanty data are available about the double inlet valve with multistage configurations in the literature. As per the author's knowledge, three-dimensional CFD modeling of multistaging with double inlet valve is not available in the literature. So, we get motivated and developed the methodology for the numerical investigation of multistaging PTC with the double inlet valve. The objective of the current study is to design a Double Inlet Two-Stage Pulse Tube Cryocooler (DITSPTC) for $20 \mathrm{~K}$ cryogenic temperatures.

This paper performs CFD simulations of IPTC for defining the methodology using the CFD software package and then the same methodology is extended to the analysis of DITSPTC. For the assessment of DITSPTC and CFD was used as a numerical tool. Cha et al. [26] PTC model and Tendolkar et al. [10] DITSPTC model considered for the analysis. The system is simulated to evaluate the performance of the TSPTC with double inlet valve.

\section{Methodology}

CFD tools are extensively utilized for numerical simulation-based analysis of systems including fluid flow, heat transport, and associated chemical reaction phenomena. In PTC, a CFD is a very useful and valuable tool for predicting the mechanism of cold formation. Modeling of the compressor employing dynamic meshing with suitable "user-defined functions" is possible with CFD Fluid, liquid, Smooth and Unconstrained in Movement (FLUENT) software. Modeling of regenerators and heat exchangers using porous media is also possible with CFD.

Geometry formation, meshing, and FLUENT setup with appropriate boundary conditions and userdefined functions are all essential of the CFD analysis of the system. The energy equation is used to understand the heat transfer mechanism and cold formation, as well as the standard $k-\varepsilon$ turbulence model to analyze the influence of turbulence kinetic energy. Helium is the working fluid for PTC, and copper and steel are the solids used for walls. Density, specific heat, thermal conductivity, viscosity, and diffusivity are all properties that can be defined in this section. In some circumstances, designers need to establish a special profile as a boundary condition, and these conditions cannot be specified using FLUENT's default settings. FLUENT offers the user-defined function option for defining such conditions.

\subsection{Governing equations}

The continuity, momentum, and energy equation are the main governing equations employed. When fluid flows in the PTC, these Equations 1, 2 and 3 must be satisfied. Conservation equations based on the continuum can be used throughout the PTC system. The mean free path of a gas molecule is often significantly less than the characteristic dimension of the PTC components.

$$
\begin{aligned}
& \frac{\partial \rho}{\partial t}+\nabla \cdot(\rho \vec{v})=0 \\
& \frac{\partial}{\partial t}(\rho \vec{v})+\nabla \cdot(\rho \vec{v} \vec{v})=-\nabla p+\nabla \cdot(\overline{\bar{\tau}}) \\
& \frac{\partial}{\partial t}(\rho E)+\nabla \cdot(\vec{v}(\rho E+p))=\nabla \cdot\left(k_{e f f} \nabla T+\left(\overline{\bar{\tau}}_{e f f} \cdot \vec{v}\right)\right)
\end{aligned}
$$

The heat exchangers may be exceptions to the above statement in some cases. The microporous structure's characteristic dimensions are comparable to, or even less than, the mean free path. So, heat exchangers are modeled using the porous media method. Thus, governing Equations 4 and 5 for the regenerator and heat exchangers.

$$
\begin{aligned}
& \frac{\partial(\varepsilon \rho)}{\partial t}+\nabla \cdot(\varepsilon \rho \vec{v})=0 \\
& \frac{\partial}{\partial t}(\varepsilon \rho \vec{v})+\nabla \cdot(\varepsilon \rho \vec{v} \vec{v})=-\varepsilon \nabla p+\nabla \cdot(\varepsilon \overline{\bar{\tau}})+S_{i}
\end{aligned}
$$

Where $S_{i}$ is an additional term for consideration of flow resistances in porous media and it is the combination of Darcy and Forchheimer term [33]:

$$
\begin{aligned}
& S_{i}=-\left(\frac{\mu}{\alpha} v_{j}+C_{2} \frac{1}{2} \rho v_{m a g} v_{j}\right) \\
& \alpha=\frac{D_{p}^{2}}{150} \frac{\varepsilon^{3}}{(1-\varepsilon)^{2}} \\
& C_{2}=\frac{3.5}{D_{p}} \frac{(1-\varepsilon)}{\varepsilon^{3}} \\
& \frac{\partial}{\partial t}\left(\varepsilon \rho_{f} E_{f}+(1-\varepsilon) \rho_{s} E_{s}\right)+\nabla \cdot\left(\vec{v}\left(\rho_{f} E_{f}+p\right)\right)= \\
& \nabla \cdot\left(k_{e f f} \nabla T+\left(\overline{\bar{\tau}}_{e f f} \cdot \vec{v}\right)\right)
\end{aligned}
$$

The theme of the current study is depicted in Figure 2. This paper performs CFD simulations of IPTC for defining the methodology using the CFD software package and then the same methodology is extended to the analysis of DITSPTC. The outcomes of system simulations are the cooldown curve, temperature contours, temperature along the length of the system, and the effect of double inlet valve opening on second stage CHX temperature 


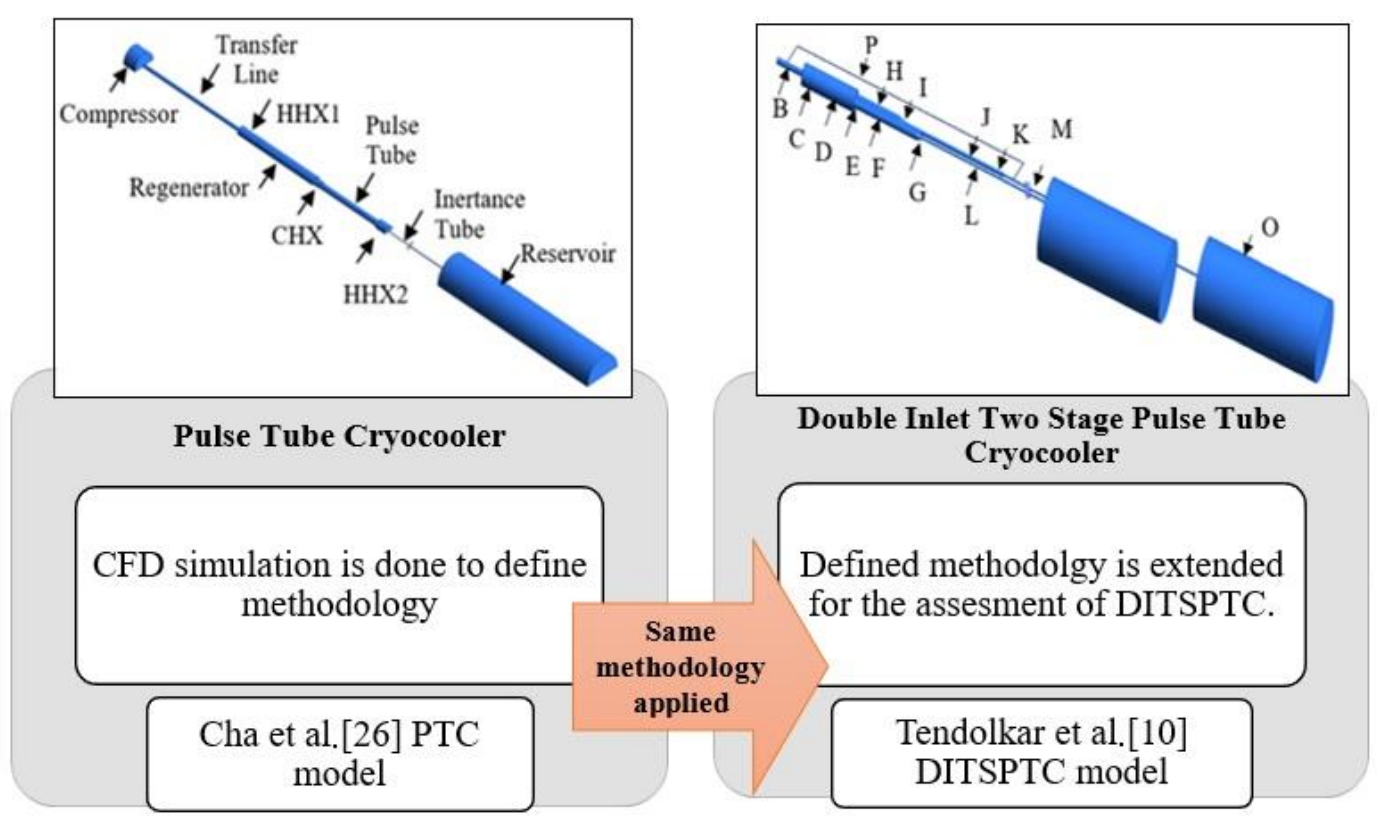

Figure 2 Theme of research paper

\subsection{Pulse tube refrigerator model}

Cha et al. [26] IPTC model is considered for the analysis. The simulations are done first using a 2D axis-symmetric model and then the same simulation is done using a 3D plane-symmetric model to get more insight into the complex processes occurring within the system.

2.2.1Model building and mesh generation

The schematic diagram for IPTC contains all cylindrical components. This can be used to model the IPTC geometry as plane-symmetric about the common plane of all the components. The "Add Frozen" function is used instead of "Add Material" for geometry creation. This is required so that different components of IPTC do not merge into each other. The dimensions of the IPTC of Cha et al. [26] model are tabularized in Table 1. The mesh is generated using Analysis of Systems (ANSYS) workbench meshing. The elements used in the mesh are mainly hexahedral and triangular for some components. This is required so that the mesh will match at the interfaces of the different components. Figure 3 and Figure 4 show the geometry created using a $2 \mathrm{D}$ axisymmetric and 3D plane-symmetric model.

The mesh is generated using ANSYS workbench meshing. The elements used in the mesh are mainly hexahedral and triangular for some components. This is required so that the mesh will match at the interfaces of the different components. The number of nodes and elements after meshing of PTC systems in the 2D axisymmetric model are 4253 and 3840 respectively, and in the 3D plane-symmetric model is 38711 and 46294 respectively. The meshing is done such that it will give the mesh-independent solution. The Mesh of different components in the $3 \mathrm{D}$ model is shown in Figure 5.

Table 1 Component dimensions of inertance pulse tube cryocooler

\begin{tabular}{lll}
\hline System & Radius $(\mathbf{m})$ & Length $(\mathbf{m})$ \\
\hline Compressor & $9.54 \times 10^{-03}$ & $7.50 \times 10^{-03}$ \\
\hline Transfer line & $1.55 \times 10^{-03}$ & $1.01 \times 10^{-01}$ \\
\hline HHX1 & $4.00 \times 10^{-03}$ & $2.00 \times 10^{-02}$ \\
\hline Regenerator & $4.00 \times 10^{-03}$ & $5.80 \times 10^{-02}$ \\
\hline CHX & $3.00 \times 10^{-03}$ & $5.70 \times 10^{-03}$ \\
\hline Pulse tube & $2.50 \times 10^{-03}$ & $6.00 \times 10^{-02}$ \\
\hline HHX2 & $4.00 \times 10^{-03}$ & $1.00 \times 10^{-02}$ \\
\hline Inertance tube & $4.25 \times 10^{-04}$ & $6.84 \times 10^{-01}$ \\
\hline Reservoir & $1.30 \times 10^{-02}$ & $1.3 \times 10^{-01}$ \\
\hline
\end{tabular}




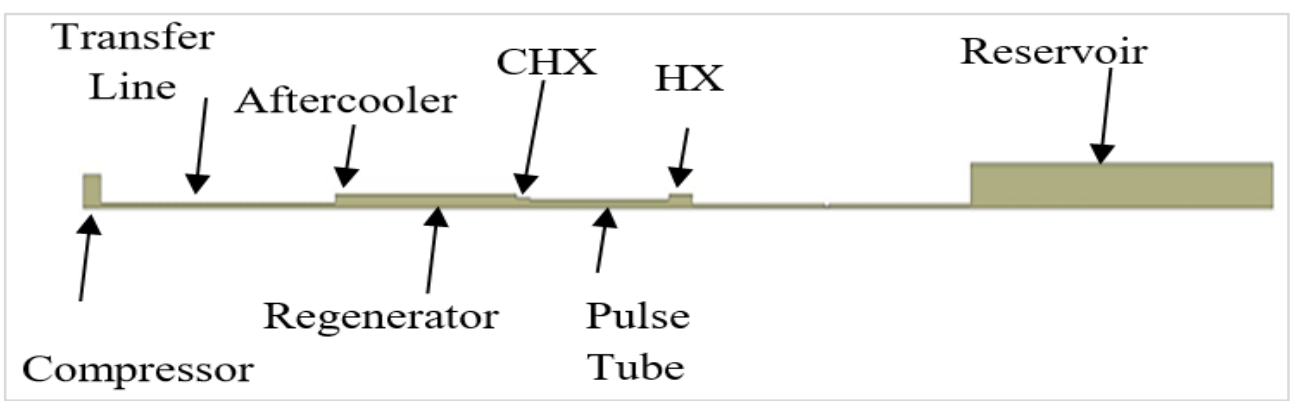

Figure $32 \mathrm{D}$ axisymmetric model of inertance pulse tube cryocooler

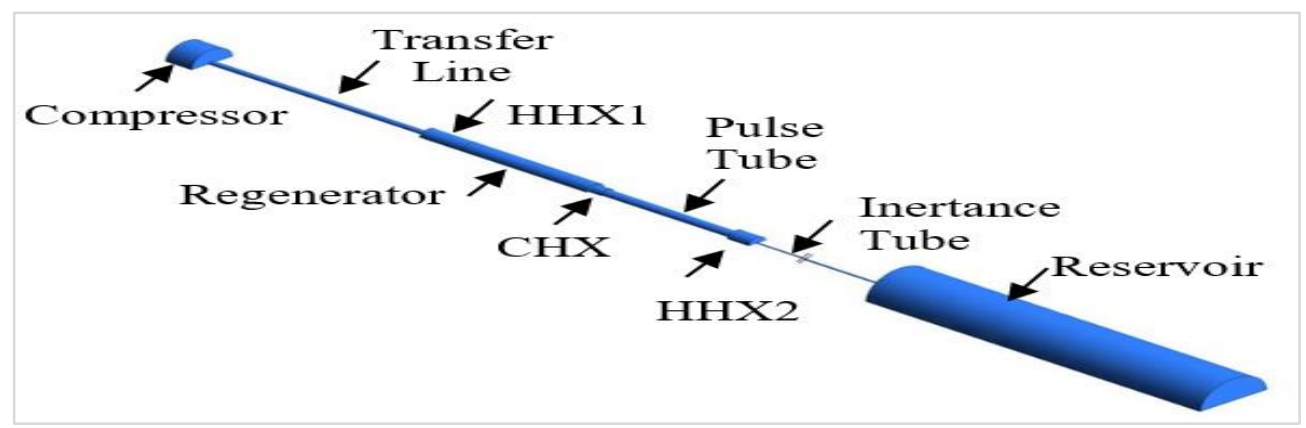

Figure 4 3D plane-symmetric model of inertance pulse tube cryocooler

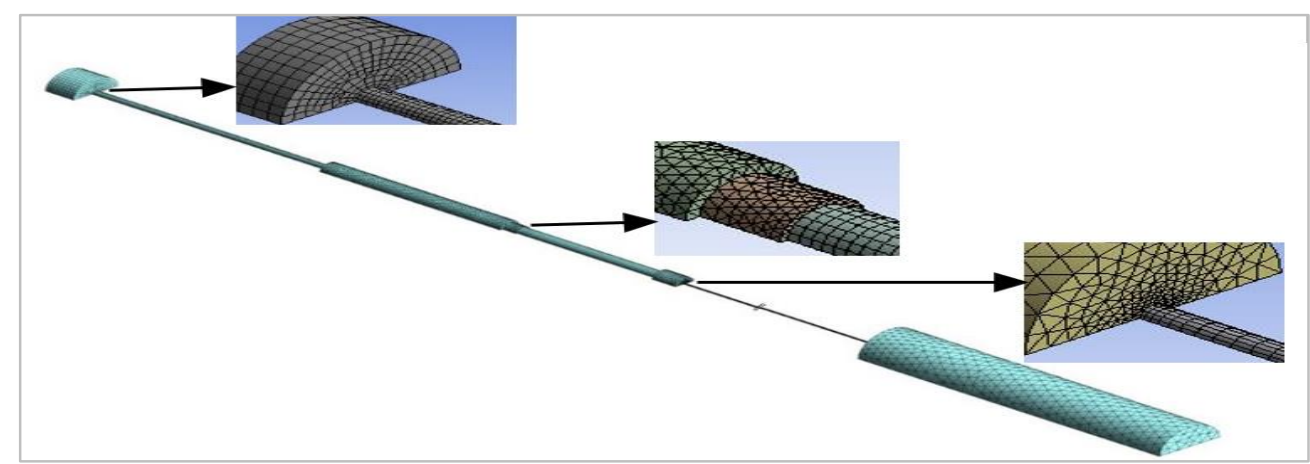

Figure 5 Mesh view of the 3D plane-symmetric mode

\subsubsection{FLUENT setup}

The FLUENT configuration for the current case is given in Table 2. In cell zone conditions, porous media can be defined for components such as aftercooler (Hot End Heat Exchangers (HHX)1), regenerator, and CHX and HHX2. The viscous (D) and inertial resistances (C) were found out for the porous zone section. The thermal equilibrium model is used in the porous zone. In the thermal equilibrium model, gas and wire mesh temperature considered the same at any time of instant. The walls of different components are also defined in the boundary conditions. The detailed cell zone and boundary conditions used to define the PTC are shown in Table 3.
There are some cases where the specific profile to be defined as a boundary condition and these conditions cannot be given through default options available in FLUENT. For defining such conditions, FLUENT provides the option of User-Defined Function (UDF). In the current case, it is achieved by giving velocity to the piston as shown in Figure 6. 100 inner steps with a time step size of $0.0003 \mathrm{~s}$ are considered for better solution convergence. With a CPU combination of 4GB of RAM and $2.40 \mathrm{GHz}$ processor, reaching a periodic steady-state takes over 30 days. 
Table 2 FLUENT configuration and operating parameters

\begin{tabular}{ll}
\hline Solver & Pressure based solver \\
\hline Computation & Double precision \\
\hline Analysis & Transient \\
\hline Turbulent and Energy Model & $\kappa-\varepsilon$ and energy enabled \\
\hline Solution Methods & SIMPLE scheme with second-order transient \\
\hline Frequency & $34 \mathrm{~Hz}$ \\
\hline
\end{tabular}

Table 3 Boundary conditions and cell zones

\begin{tabular}{|c|c|c|}
\hline System & Cell zone & Boundary conditions \\
\hline Compressor & Solid: Steel & Adiabatic \\
\hline Transfer line & Solid: Steel & Adiabatic \\
\hline HHX1 & $\begin{array}{l}\text { Porous zone: Copper, Porosity: } 0.69 \\
\text { D: } 9.44 \times 109 \mathrm{~m}-2, \mathrm{C}: 76090 \mathrm{~m}-1\end{array}$ & Wall Temperature is $300 \mathrm{~K}$ \\
\hline Regenerator & $\begin{array}{l}\text { Porous zone: Steel, Porosity: } 0.69 \\
\text { D: } 9.44 \times 1010 \mathrm{~m}-2, \mathrm{C}: 76090 \mathrm{~m}-1\end{array}$ & Adiabatic \\
\hline CHX & $\begin{array}{l}\text { Porous zone: Copper, Porosity: } 0.69 \\
\text { D: } 9.44 \times 109 \mathrm{~m}-2, \mathrm{C}: 76090 \mathrm{~m}-1\end{array}$ & Adiabatic \\
\hline Pulse tube & Solid: Steel & Adiabatic \\
\hline HHX2 & $\begin{array}{l}\text { Porous zone: Copper, Porosity: } 0.69 \\
\text { D: } 9.44 \times 109 \mathrm{~m}-2, \mathrm{C}: 76090 \mathrm{~m}-1\end{array}$ & Wall Temperature is $300 \mathrm{~K}$ \\
\hline Inertance tube & Solid: Copper & Adiabatic \\
\hline Reservoir & Solid: Steel & Adiabatic \\
\hline
\end{tabular}

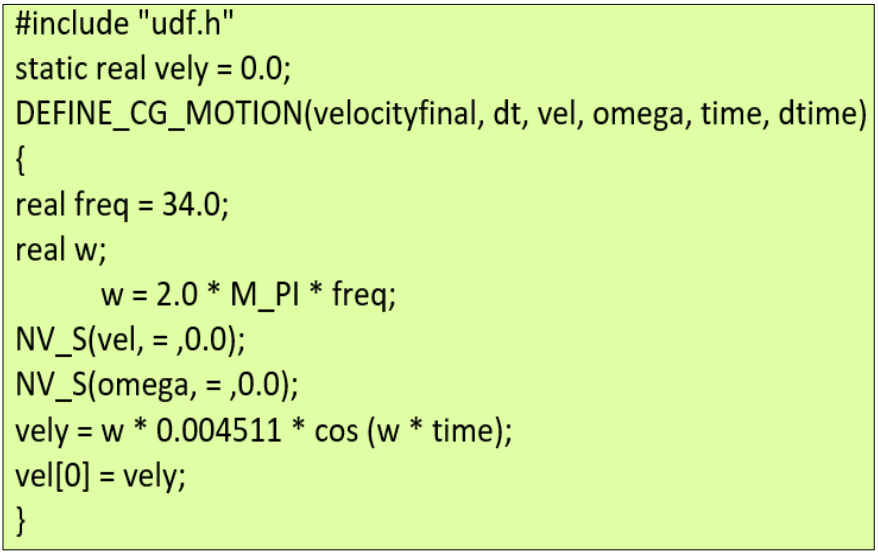

Figure 6 User defined function

\subsubsection{Results of IPTC model}

ITPC model is simulated and the results obtained from the simulation are compared with Cha et al. [26] model. The time-varying temperature at $\mathrm{CHX}$ is shown in Figure 7. The cyclic steady temperature achieved at $\mathrm{CHX}$ by $2 \mathrm{D}$ axisymmetric and 3D planesymmetric modeling is $75.88 \mathrm{~K}$ and $76 \mathrm{~K}$ respectively. Results obtained from 2D axis-symmetric and 3D plane-symmetric models adequately agree with the results of Cha et al. [26]. The change between experimental and numerical analysis is due to the assumption of an ideal gas and no wall thickness consideration. So the single-stage IPTC is validated. The same methodology can be extended for the simulation of the double inlet two-stage IPTC. To study the temperature distribution in different 771 components, the temperature values are obtained at different locations along the centerline of the components. These values are the average value over a cycle for a particular location. The radial temperature variation in the different components is negligible. The temperature along the axial direction for the IPTC is displayed in Figure 8. During the PTC operation, pressurization in the compressor leads to an increase in pressure and temperature. The heat generated due to compression is rejected through the aftercooler which brings down the temperature to the ambient. The rest of the energy that is not rejected through the aftercooler is carried through by the enthalpy flow in the regenerator. Heat is rejected to the wire mesh resulting in the temperature reduction of helium gas. 
Mahmadrafik Choudhari et al.

Temperature increases along the length of the pulse tube due to pressure variation. The hot end heat exchanger is employed after the pulse tube to maintain ambient temperature. The backward flow occurs as a result of depressurization. Phase shift obtained between pressure and mass flow due to the phaseshifting mechanism resulting in the refrigeration at $\mathrm{CHX}$. Figure 9 shows the temperature contours for the components of IPTC which are, regenerator, CHX, and pulse tube. The mass flow rate with pressure variation graph is crucial and useful for the optimization of the refrigeration effect. It is shown in Figure 10. The validation of the Cha et al. [26] model is done successfully and the same methodology is applied to double inlet two-stage PTC. The model that is used here for simulation and analysis is taken from Tendolkar et al. [10] DITSPTC model.

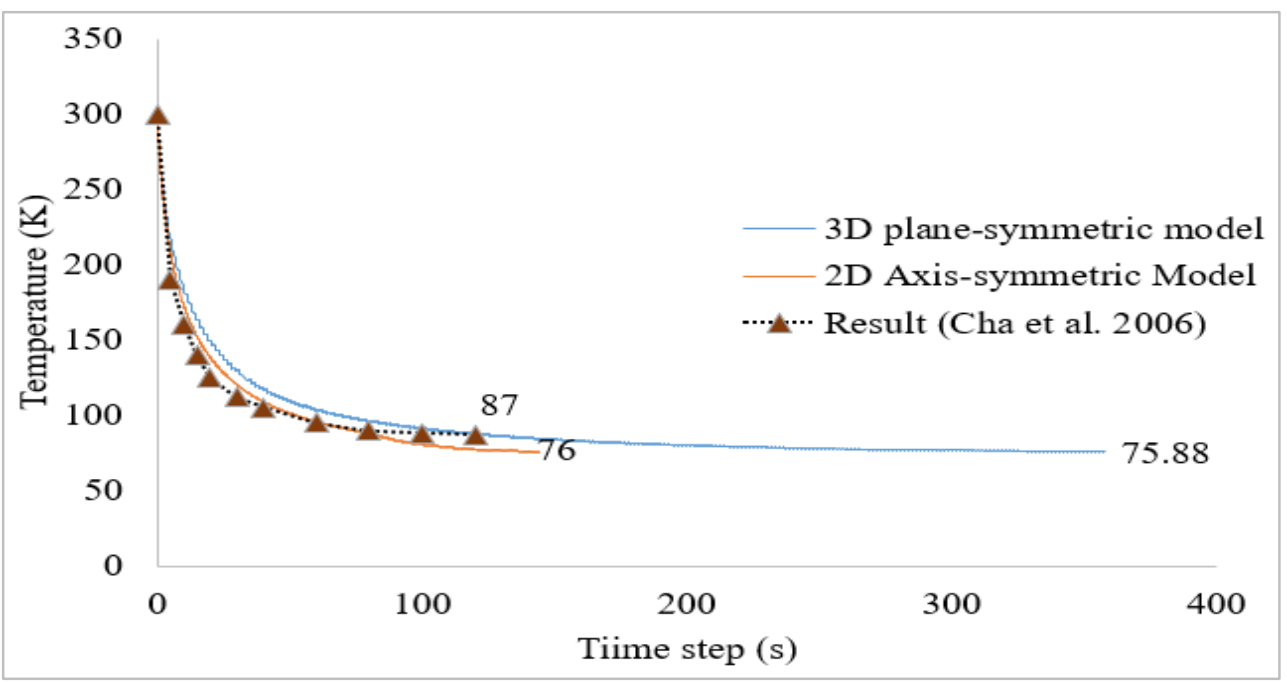

Figure 7 Cooldown curve of inertance pulse tube cryocooler

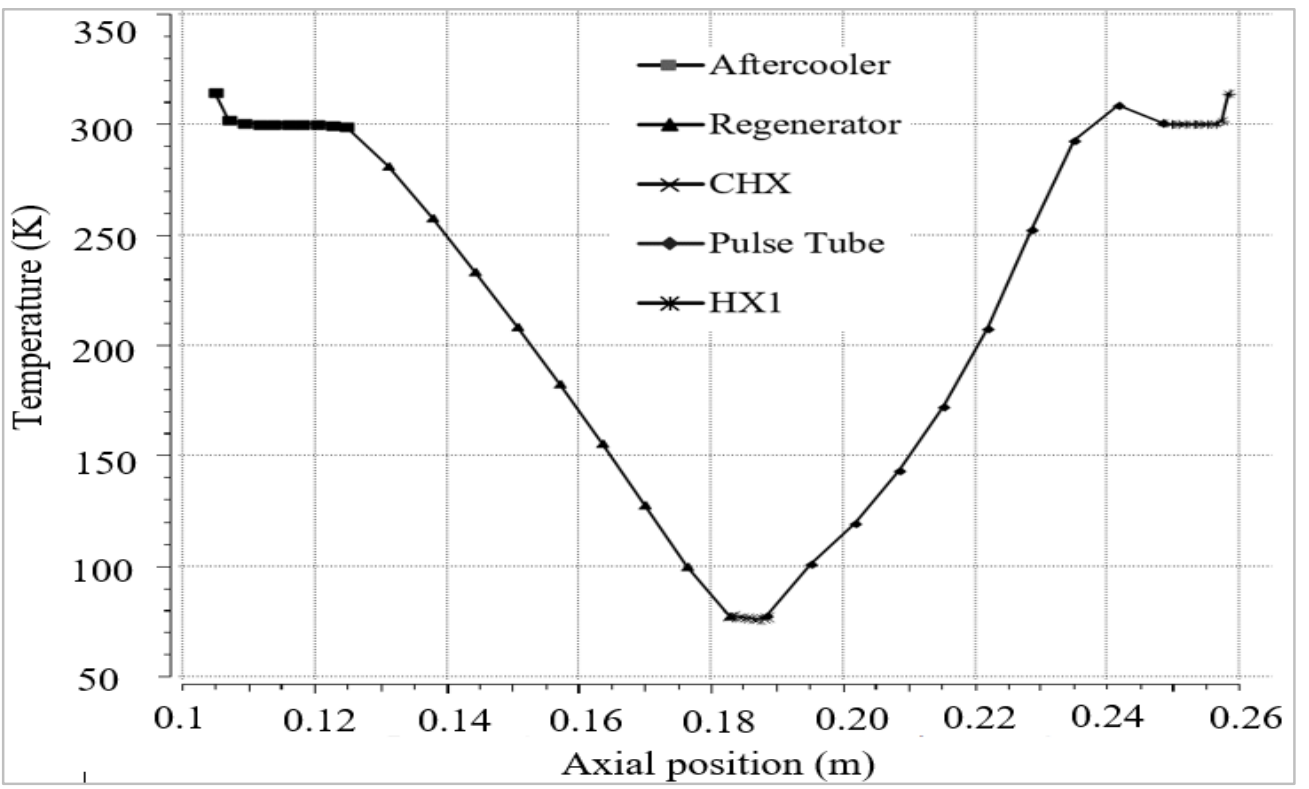

Figure 8 Temperature along the length of IPTC 


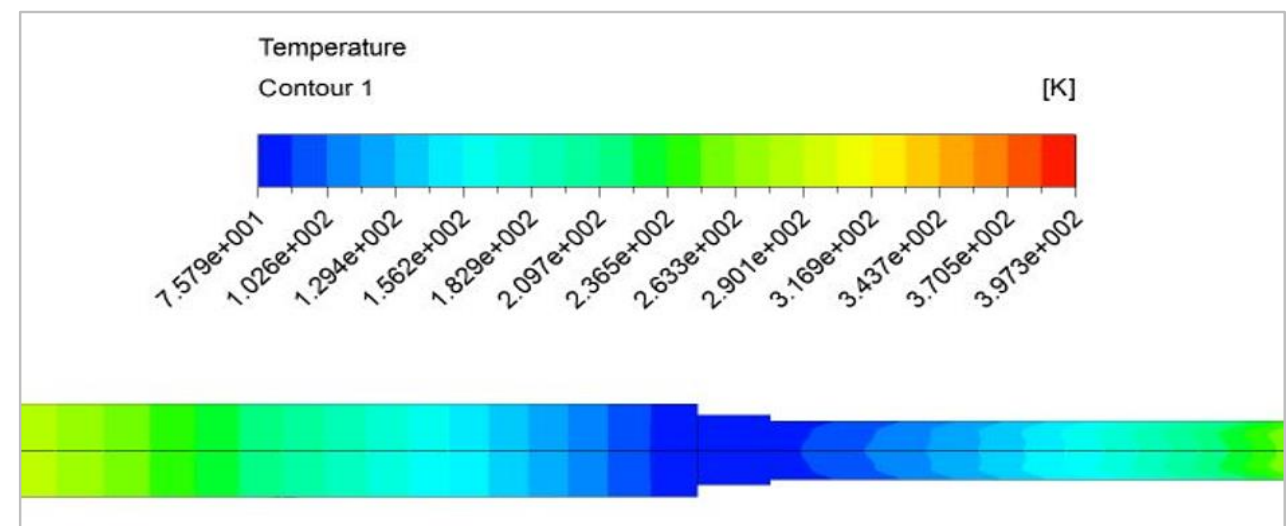

Figure 9 Temperature contour of inertance PTC

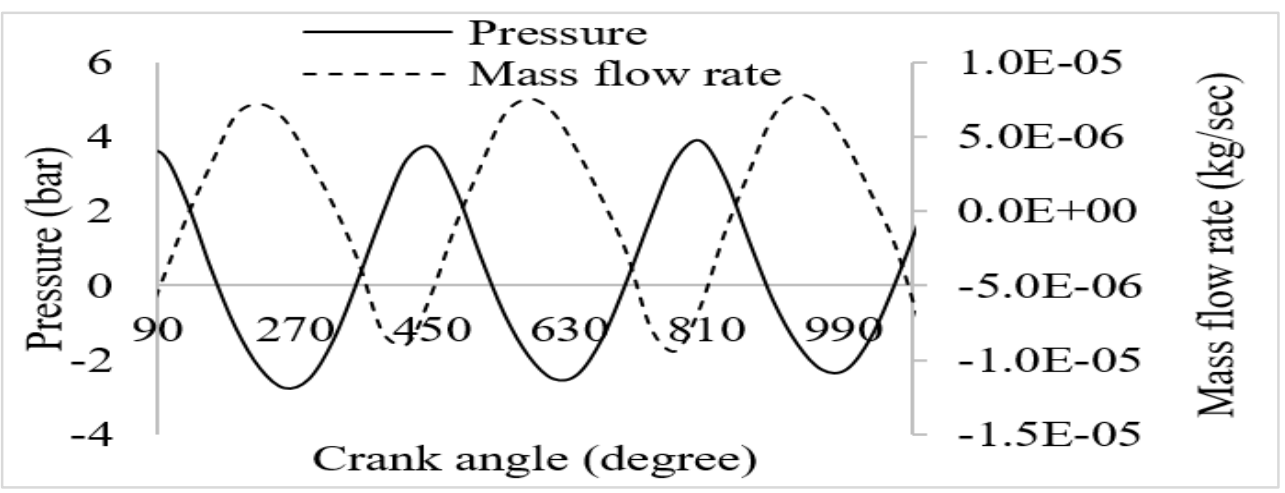

Figure 10 Pressure and mass flow variation at $\mathrm{CHX}$

\subsection{Double inlet two-stage inertance pulse tube} cryocooler

The DITSPTC system consists of a double inlet valve and two stages of PTC. The double inlet valve optimizes the phase shift and the second stage gives the required cryogenic temperature. Tendolkar et al. [10] DITSPTC model is considered for the analysis. Numerical analysis of DITSPTC is done and validated with the experimental results obtained by Tendolkar et al. [10].

2.3.1Model building and mesh generation

The 3D plane-symmetric model is generated using the ANSYS workbench. DI valve with $425 \mathrm{~mm}$ length and $1 \mathrm{~mm}$ diameter is incorporated between the transfer line and hot end heat exchanger side of the second stage to improve the performance. The dimensions of the Tendolkar et al. [10] DITSPTC model are tabularized in Table 4. The DITSPTC model is shown in Figure 11. The optimal meshing for the DITSPTC is done using hexahedral and tetrahedron elements. The Mesh of different components in the 3D model is shown in Figure 12. The test for grid independency is done and the optimum number of nodes and elements after meshing of the DITSPTC system in the 3D planesymmetric model are 450695 and 1027097 respectively. Figure 13 shows the grid independency test for the DITSPTC model.

Table 4 Dimensions of DITSPTC model

\begin{tabular}{lll}
\hline Component & Radius $(\mathbf{m})$ & Length $(\mathbf{m})$ \\
\hline $\mathrm{B}$ (Transfer line) & $3.00 \times 10^{-03}$ & $3.60 \times 10^{-02}$ \\
\hline $\mathrm{C}$ (Aftercooler) & $1.00 \times 10^{-02}$ & $1.30 \times 10^{-02}$ \\
\hline $\mathrm{D}$ (Regenerator 1) & $1.00 \times 10^{-02}$ & $5.50 \times 10^{-02}$ \\
\hline $\mathrm{E}$ (CHX 1) & $1.00 \times 10^{-02}$ & $7.60 \times 10^{-03}$ \\
\hline $\mathrm{F}$ (Pulse tube 1) & $4.00 \times 10^{-03}$ & $9.00 \times 10^{-02}$ \\
\hline $\mathrm{G}$ (HHX 1) & $4.00 \times 10^{-03}$ & $1.00 \times 10^{-02}$ \\
\hline $\mathrm{L}$ (Inertance tube 1) & $1.15 \times 10^{-03}$ & 2.00 \\
\hline $\mathrm{N}$ (Reservoir 1) & $1.15 \times 10^{-03}$ & $1.76 \times 10^{-01}$ \\
\hline
\end{tabular}


Mahmadrafik Choudhari et al.

\begin{tabular}{lll}
\hline Component & Radius (m) & Length (m) \\
\hline H (Regenerator 2) & $4.50 \times 10^{-03}$ & $6.00 \times 10^{-02}$ \\
\hline I (CHX 2) & $4.50 \times 10^{-03}$ & $1.12 \times 10^{-02}$ \\
\hline J (Pulse tube 2) & $2.00 \times 10^{-03}$ & $1.20 \times 10^{-01}$ \\
\hline K (HHX 2) & $2.00 \times 10^{-03}$ & $2.10 \times 10^{-02}$ \\
\hline M (Inertance tube 2) & $2.00 \times 10^{-03}$ & 3.00 \\
\hline P(Double inlet valve) & $1.15 \times 10^{-03}$ & 0.425 \\
\hline O (Reservoir 2) & $0.5 \times 10^{-03}$ & $1.76 \times 10^{-01}$ \\
\hline
\end{tabular}

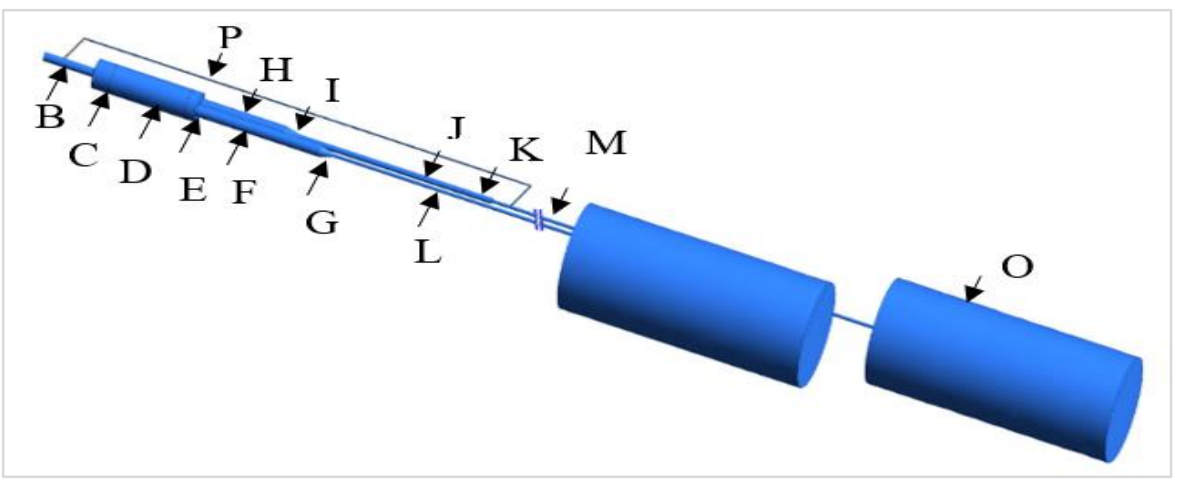

Figure 11 Double inlet two-stage inertance pulse tube cryocooler model

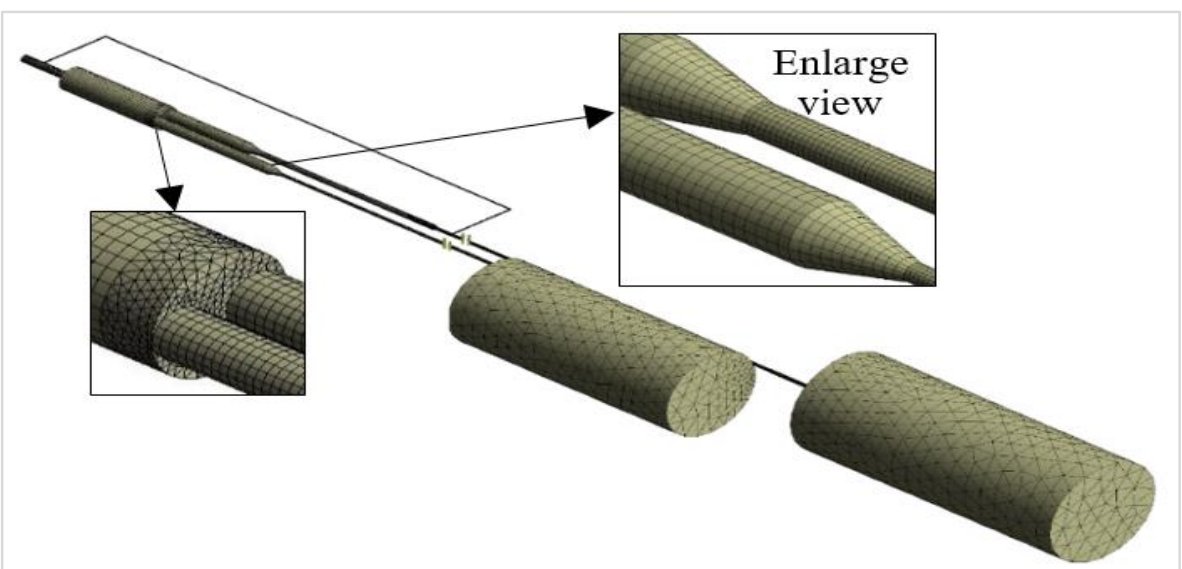

Figure 12 Mesh view of Double Inlet Two-Stage Inertance Pulse Tube Cryocooler (DITSIPTC)

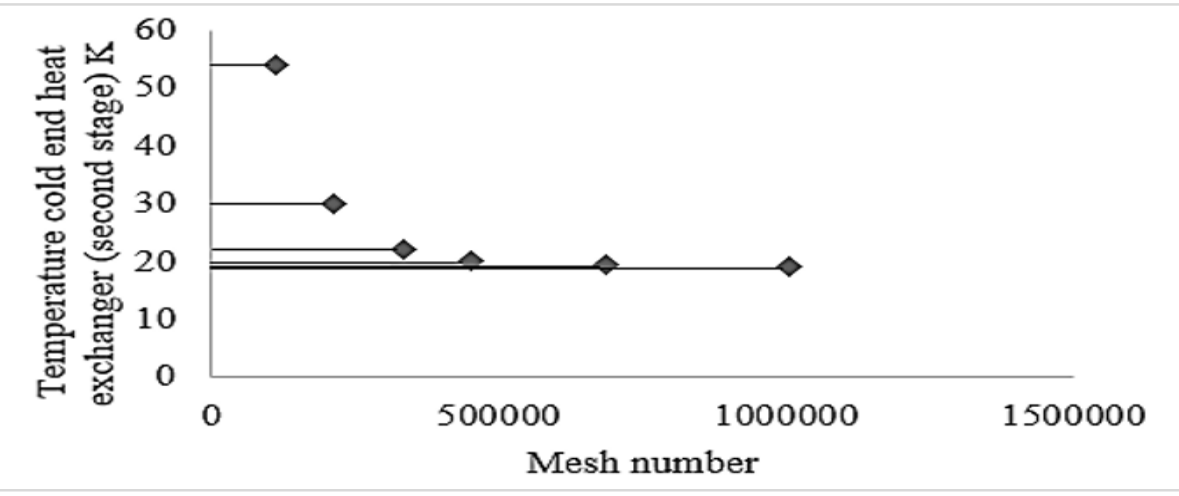

Figure 13 Mesh independency test 


\subsubsection{FLUENT setup}

The FLUENT configuration for the current case is the same as the previous single-stage IPTC. Operating system pressure and frequency are 20 bar and $70 \mathrm{~Hz}$ respectively. In cell zone conditions, porous media can be defined for the heat exchangers. The viscous and inertial resistances are found out for the porous zone. There is continuous pressurization and depressurization occur in the system. So, the fluid flow considered in the system is compressible. In all the components of the system, flow is considered laminar. The detailed boundary conditions and respective cell zones are shown in Table 5.

Complete list of abbreviations is shown in Appendix I.

Table 5 Boundary conditions and cell zones

\begin{tabular}{|c|c|c|}
\hline System & Cell zone & Boundary conditions \\
\hline Compressor, & Solid: Steel & Adiabatic \\
\hline Transfer line & Solid: Steel & Adiabatic \\
\hline $\begin{array}{l}\text { Aftercooler (HHX1), HHX2 - } \\
\text { stage one }\end{array}$ & $\begin{array}{l}\text { Porous zone: Copper, Porosity }(\varphi): 0.69 \\
\text { D: } 1.2987 \times 10^{9} \mathrm{~m}^{-2}, \mathrm{C}: 9234 \mathrm{~m}^{-1},\end{array}$ & Wall Temperature: $300 \mathrm{~K}$ \\
\hline Regenerator 1 & $\begin{array}{l}\text { Porous zone: Steel, Porosity }(\varphi): 0.686 \\
\text { D: } 2.083 \times 10^{10} \mathrm{~m}^{-2}, \text { C: } 34189 \mathrm{~m}^{-1}\end{array}$ & Adiabatic \\
\hline Regenerator 2 & $\begin{array}{l}\text { Porous zone: Steel, Porosity }(\varphi): 0.607 \\
\text { D: } 4.166 \times 10^{10} \mathrm{~m}^{-2}, \text { C: } 51707 \mathrm{~m}^{-1}\end{array}$ & Adiabatic \\
\hline CHX 1 and CHX 2 & $\begin{array}{l}\text { Porous zone: Copper, Porosity }(\varphi): 0.69 \\
\text { D: } 1.2987 \times 10^{9} \mathrm{~m}^{-2}, \mathrm{C}: 6905 \mathrm{~m}^{-1}\end{array}$ & Adiabatic \\
\hline $\begin{array}{l}\text { Double Inlet Valve, Pulse Tube } \\
1 \text { and } 2\end{array}$ & Solid: Steel & Adiabatic \\
\hline HHX 1 and HHX 2 - stage two & $\begin{array}{l}\text { Porous zone: Copper, Porosity }(\varphi): 0.691 \\
\text { D: } 1.2987 \times 10^{9} \mathrm{~m}^{-2}, \mathrm{C}: 7883 \mathrm{~m}^{-1}\end{array}$ & Adiabatic \\
\hline Inertance tubes & Solid: Copper & Adiabatic \\
\hline Reservoirs & Solid: Steel & Adiabatic \\
\hline
\end{tabular}

\section{Results and discussions}

The temperature variations of the first and secondstage cold end heat exchangers are plotted in Figure 14. For the first stage and second stage regenerators, 400 size wire mesh and 500 size wire mesh are used. The first stage $\mathrm{CHX}$ and second stage regenerator are thermally coupled. So, cooling at the second stage depends on the temperature of the first stage regenerator. The initial trends of cyclic temperature at CHX1 and CHX2 show that CHX1 temperature is decreasing at a faster rate than $\mathrm{CHX} 2$ temperature after $225 \mathrm{~K}$, this is since there is a reduced mass flow through the second stage regenerator due to its finer mesh.

The simulation of DITSPTC was carried out till the cyclic steady temperature achieved at both the CHX1 and CHX2. Temperature contour is given to display the temperature in the DITSPTC system at a time instant. The temperature achieved at $\mathrm{CHX} 1$ is $95 \mathrm{~K}$ and at $\mathrm{CHX} 2$ is $20 \mathrm{~K}$ respectively, which are in close relation with experimental values of Tendolkar's DITSPTC $96 \mathrm{~K}$ and $23.56 \mathrm{~K}$ respectively shown in Figure 15 and Figure 16. The temperature contour showing the temperature of DITSPTC at the cyclic steady state of the system. The cyclic steady temperature at $\mathrm{CHX} 1$ and $\mathrm{CHX} 2$ are confirmed by both the cooldown curve and temperature contours. The temperature difference in the numerical and experimental analysis is induced due to the assumption of an ideal gas and no wall thickness consideration. Hence, the model has been successfully applied and validated to double inlet two-stage PTC.

The performance of the DITSPTC is strongly influenced by the setting of a double inlet valve at the second stage. The distribution of total gas from the compressor to the stages is significant since it is mostly governed by the area available through the double inlet valve. Figure 17 shows the variation of second stage $\mathrm{CHX}$ temperature with the percentage opening of the double inlet valve. DITSPTC performs better when the double inlet valve fully open.

In CFD simulation of PTC and DITSPTC, the regenerator is modeled as the porous zone. Regenerator analysis can be done by using the thermal equilibrium model or thermal non-equilibrium model. The temperature of gas and wire mesh is considered as same at any instant of time in the thermal equilibrium model. For avoiding the complexity of the problem, the thermal equilibrium model is used. The present study considered fluid domain with no wall thickness. 
Mahmadrafik Choudhari et al.

In the near future, the numerical assessment of DITSPTC can be done by considering the thermal non-equilibrium model and thickness of the wall to address the conduction losses.

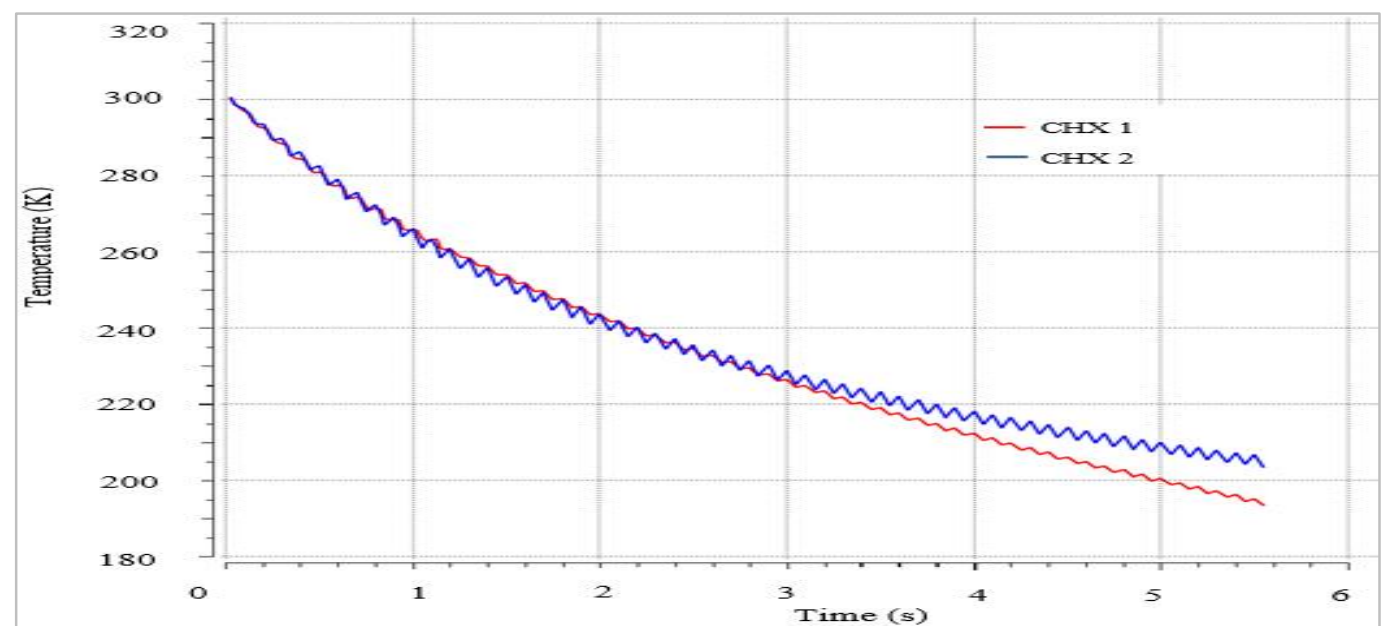

Figure 14 Initial trend of cooldown curve for CHX1 and CHX 2

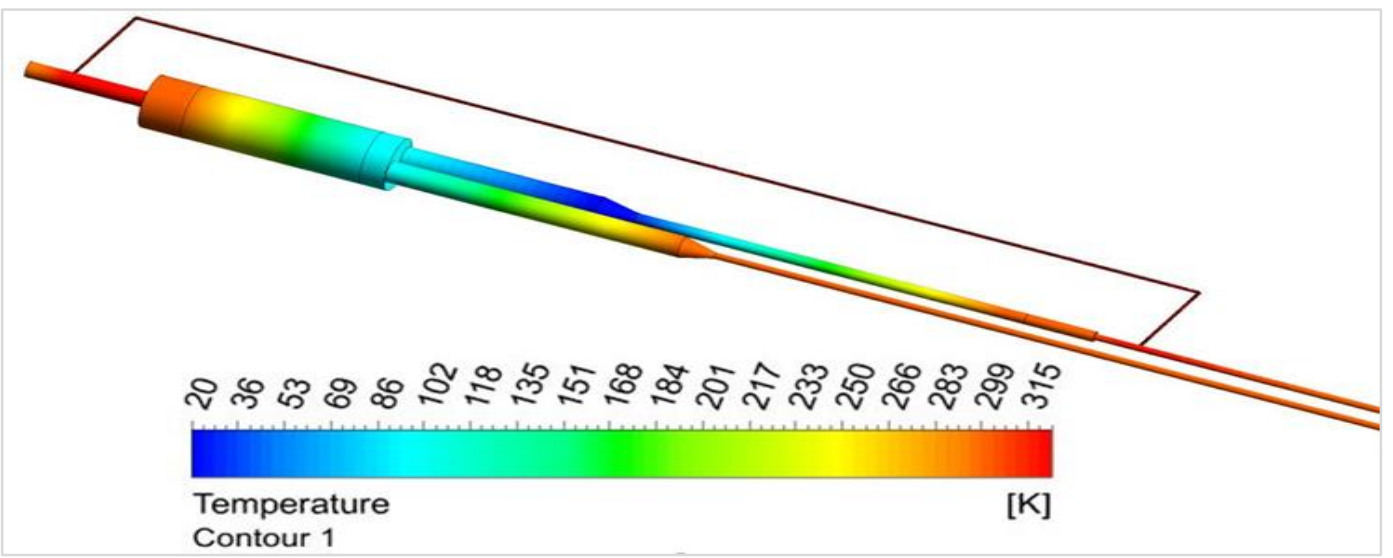

Figure 15 Temperature contour for DITSIPTC

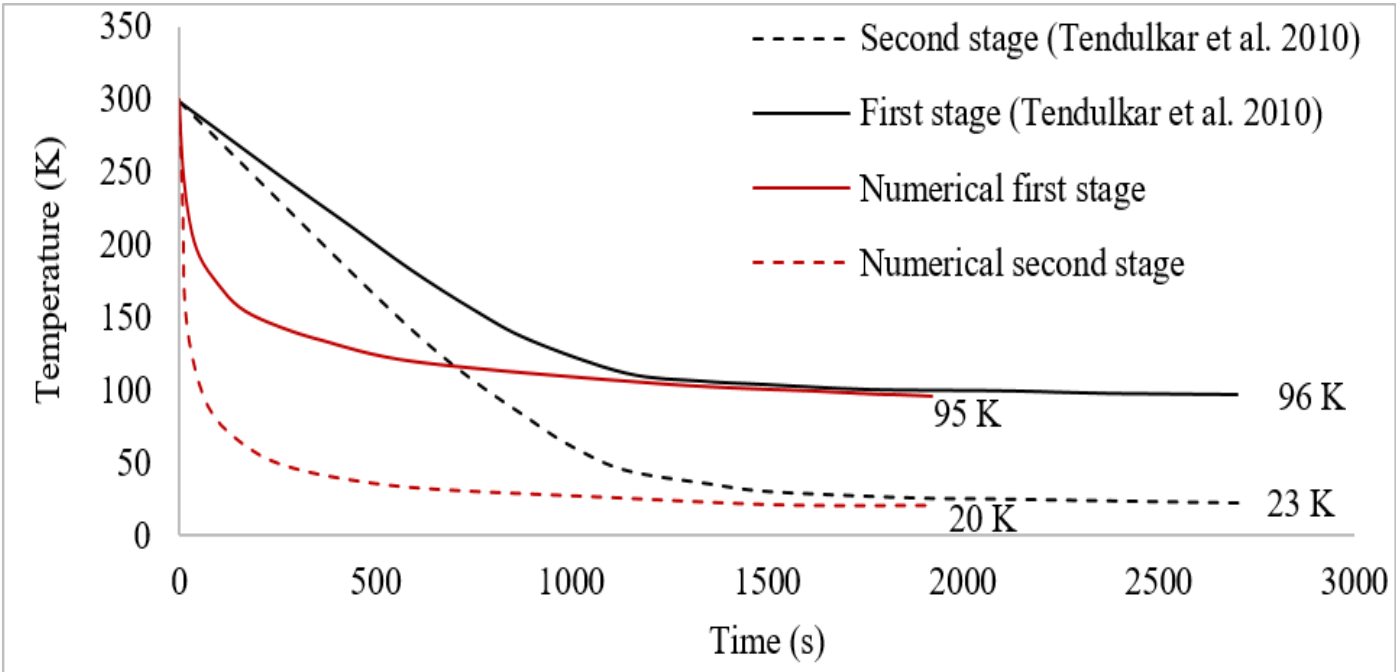

Figure 16 Cooldown curves for CHX1 and CHX2 


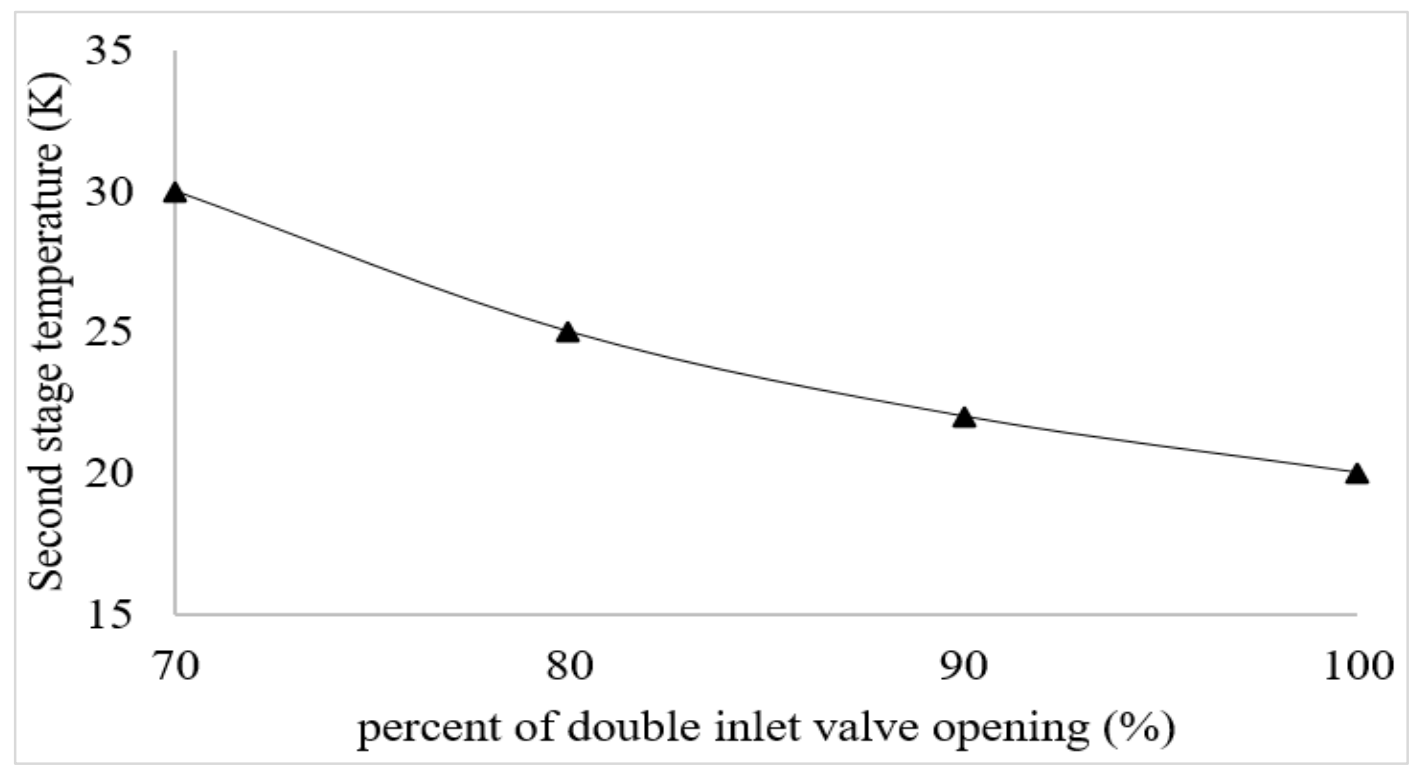

Figure 17 Second stage CHX temperature vs double inlet valve opening

\section{Conclusion}

The DITSPTC is numerically simulated using a 3D plane-symmetric model for the lowest attainable temperature. This study performed CFD simulations of PTC to define the approach, which is then extended to the analysis of a DITSPTC using the same methodology. CFD simulations of PTC yielded cyclic steady-state temperatures of $76 \mathrm{~K}$ and $75.88 \mathrm{~K}$ for the 2D axis-symmetric and 3D plane-symmetric models respectively. The proposed simulation methodology adequately agrees with the stated literature. The simulations are performed using the same methodology for DITSPTC at the frequency of $70 \mathrm{~Hz}$ and average pressure of 20 bar. At the first and second stages, simulations yielded minimum temperatures of $95 \mathrm{~K}$ and $20 \mathrm{~K}$, respectively. CFD simulations are following experimental results of reported literature adequately. The performance of the DITSPTC is strongly influenced by the setting of a double inlet valve in the second stage. The system functions best when the double inlet valve is fully opened. The proposed methodology can be reckoned to simulate the PTC during the system design phase, as per the above analysis.

\section{Acknowledgment}

The authors gratefully acknowledge the Director and Head MED, Walchand College of Engineering for the continuous support. No fund/grant is received for this research work.

\section{Conflicts of interest}

The authors have no conflicts of interest to declare.

\section{References}

[1] Gifford WE, Longsworth RC. Pulse-tube refrigeration. Trans ASME. 1964; 86(3): 264-8.

[2] Mikulin EI, Tarasov AA, Shkrebyonock MP. Lowtemperature expansion pulse tubes. In advances in cryogenic engineering 1984 (pp. 629-37). Springer, Boston, MA.

[3] Shaowei Z, Peiyi W, Zhongqi C. Double inlet pulse tube refrigerators: an important improvement. Cryogenics. 1990; 30(6):514-20.

[4] Zhu SW, Zhou SL, Yoshimura N, Matsubara Y. Phase shift effect of the long neck tube for the pulse tube refrigerator. In cryocoolers 91997 (pp. 269-78). Springer, Boston, MA.

[5] Hu JY, Ren J, Luo EC, Dai W. Study on the inertance tube and double-inlet phase shifting modes in pulse tube refrigerators. Energy Conversion and Management. 2011; 52(2):1077-85.

[6] Roy PC, Kundu B. Thermodynamic modeling of a pulse tube refrigeration system. Journal of Thermal Engineering. 2018; 4(1):1668-79.

[7] Getie MZ, Lanzetta F, Begot S, Admassu BT, Hassen AA. Reversed regenerative stirling cycle machine for refrigeration application: a review. International Journal of Refrigeration. 2020; 118: 173-87.

[8] Dang H, Bao D, Gao Z, Zhang T, Tan J, Zha R, et al. Theoretical modeling and experimental verifications of the single-compressor-driven three-stage stirling-type pulse tube cryocooler. Frontiers in Energy. 2019; 13:450-63.

[9] Yang LW, Liang JT, Zhou Y, Wang JJ. Research of two-stage co-axial pulse tube coolers driven by a valveless compressor. In Cryocoolers 102002 (pp. 2338). Springer, Boston, MA.

[10] Tendolkar MV, Narayankhedkar KG, Atrey MD. Experimental investigations on $20 \mathrm{~K}$ stirling-type two- 
stage pulse tube cryocooler with inline configuration. International cryocooler conference 2011(pp.309-15).

[11] Dietrich M, Thummes G. Two-stage high frequency pulse tube cooler for refrigeration at $25 \mathrm{~K}$. Cryogenics. 2010; 50(4):281-6.

[12] Wu X, Chen L, Liu X, Wang J, Zhou Y, Wang J. A 15K two-stage gas-coupled Stirling-type pulse tube cryocooler. In IOP conference series: materials science and engineering 2019 (pp. 1-5). IOP Publishing.

[13] Pang X, Wang X, Dai W, Luo E, Li H, Ma S. An integral hybrid two-stage pulse tube cooler with improved efficiency. Cryogenics. 2019; 98:107-12.

[14] Pang X, Wang X, Dai W, Li H, Wu Y, Luo E. Theoretical and experimental study of a gas-coupled two-stage pulse tube cooler with stepped warm displacer as the phase shifter. Cryogenics. 2018; 92:3640.

[15] Zhu S, Lin Y. Fundament of input power distribution and phase shifter functions of a step displacer type twostage pulse tube refrigerator. International Journal of Refrigeration. 2020; 113:31-7.

[16] Lin Y, Guo Z, Guo Z, Zhu S. Experimental investigation of the connecting tube effect on a step displacer type two stage pulse tube refrigerator. Applied Thermal Engineering. 2020.

[17] Liu B, Jiang Z, Ying K, Zhu H, Liu S, Wen F, et al. A high efficiency Stirling/pulse tube hybrid cryocooler operating at $35 \mathrm{~K} / 85 \mathrm{~K}$. Cryogenics. 2019; 101:137-40.

[18] Dang H, Bao D, Zhang T, Tan J, Zha R, Li J, et al. Theoretical and experimental investigations on the three-stage stirling-type pulse tube cryocooler using cryogenic phase-shifting approach and mixed regenerator matrices. Cryogenics. 2018; 93:7-16.

[19] Jeong S, Jin L. Thermodynamic performance comparison of a two-stage cryocooler and cascade cryocoolers with thermal anchoring for precooling purpose. Cryogenics. 2019; 99:32-8.

[20] Atrey MD, Bapat SL, Narayankhedkar KG. Cyclic simulation of stirling cryocoolers. Cryogenics. 1990; 30(4):341-7.

[21] Zhu SW, Chen ZQ. Isothermal model of pulse tube refrigerator. Cryogenics. 1994; 34(7):591-5.

[22] Kasthurirengan S, Srinivasa G, Karthik GS, Ramesh KP, Shafi KA. Experimental studies on a two stage pulse tube cryocooler reaching $2.5 \mathrm{~K}$. In AIP conference proceedings 2008 (pp. 85-92). American Institute of Physics.

[23] Gawali BS, Narayankhedkar KG. Performance prediction and experimental investigations on integral pulse tube cryocooler for $15 \mathrm{~W}$ at $70 \mathrm{~K}$ using indigenously developed linear compressor. In AIP conference proceedings 2006 (pp. 11-8). American Institute of Physics.

[24] Krishnappa GB, Madhu D, Kasthurirengan S. Comparison of 1D and 2D flow numerical analysis applied to two stage pulse tube cryocooler. In AIP conference proceedings 2012 (pp. 1157-64). American Institute of Physics.
[25] Flake B, Razani A. Modeling pulse tube cryocoolers with CFD. In AIP conference proceedings 2004 (pp. 1493-9). American Institute of Physics.

[26] Cha JS, Ghiaasiaan SM, Desai PV, Harvey JP, Kirkconnell CS. Multi-dimensional flow effects in pulse tube refrigerators. Cryogenics. 2006; 46(9):65865.

[27] Kumar P, Gupta AK, Sahoo RK, Jena DP. Numerical investigation of a $3 \mathrm{D}$ inertance pulse tube refrigerator from design prospective. Cryogenics. 2019; 98:125-38.

[28] Choudhari MS, Gawali BS, Malwe P. Numerical analysis of inertance pulse tube refrigerator. In IOP conference series: materials science and engineering 2021 (pp.1-8). IOP Publishing.

[29] Arslan M, Farooq M, Naqvi M, Sultan U, Tahir ZU, Nawaz S, et al. Impact of varying load conditions and cooling energy comparison of a double-inlet pulse tube refrigerator. Processes. 2020; 8(3):1-15.

[30] Panda D, Kumar M, Satapathy AK, Sarangi SK, Sahoo RK. Performance evaluation of a GM-type double inlet pulse tube refrigerator using artificial intelligence approach with experimental validation. Arabian Journal for Science and Engineering. 2020; 45:9579-97.

[31] Panda D, Satapathy AK, Sarangi SK. Thermoeconomic performance optimization of an orifice pulse tube refrigerator. Science and Technology for the Built Environment. 2020; 26(4):492-510.

[32] Panda D, Kumar M, Satapathy AK, Sarangi SK. Optimal design of thermal performance of an orifice pulse tube refrigerator. Journal of Thermal Analysis and Calorimetry. 2021; 143:3589-609.

[33] Manual UD. Ansys Fluent 12.0. Theory Guide. Canonsburg, PA. 2009.

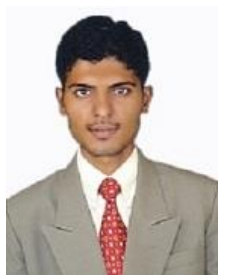

Mahmadrafik Choudhari is a full-time Ph.D. research scholar in the WCE, Sangli. His research work focuses on the areas of Heat Exchangers, Pulse Tube Cryocoolers, Heat Transfer Enhancement, and CFD. He has a total teaching experience of around three years. He has published 07 research papers in various standard journals and conferences on the international and national levels.

Email: mahmadrafik.choudhari@walchandsangli.ac.in

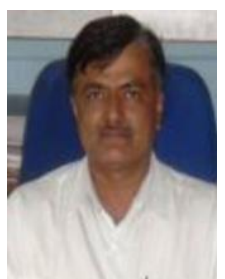

Bajirao Gawali is a Professor in the WCE, Sangli. His research work focuses on the areas of Heat Transfer, Fluid Dynamics, Refrigeration and Air Conditioning, CFD. He has a total teaching experience of around 28 years. He has published 55 research papers in various standard journals and conferences on the international and national levels. Email: bajirao.gawali@walchandsangli.ac.in 


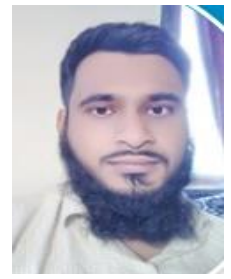

Mohammedadil Momin is a postgraduate research scholar from the WCE, Sangli. His research work focuses on the areas of Heat Transfer, Fluid Dynamics, Refrigeration and Air Conditioning, CFD. He is researching double inlet two-stage pulse tube cryocooler.

Email: mominmohammedadil@gmail.com

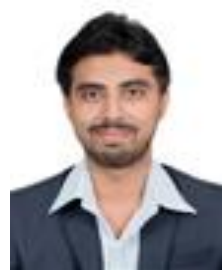

Prateek Malwe is a full-time Ph.D. research scholar in the WCE, Sangli. His research work focuses on the areas of Refrigeration, Cold Chain, Energy, And Exergy Analysis, Waste Heat Recovery, and The Organic Rankine Cycle. He has a total teaching experience of around three and a half years. He has published 17 research papers in various standard journals and conferences on the international and national levels.

Email: prateek0519@gmail.com

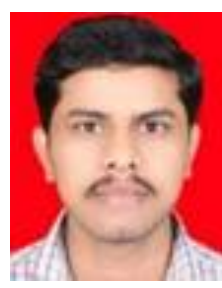

Nandkishor Deshmukh is a full-time $\mathrm{Ph} . \mathrm{D}$. research scholar in the WCE, Sangli. His research work focuses on the areas of Liquid Desiccant Cooling Systems, Heat Transfer, Fluid Dynamics, Refrigeration, and Air Conditioning. He has a total teaching experience of around three years. He has published 04 research papers in various standard journals and conferences on the international and national levels. Email: nsd.kishor@gmail.com

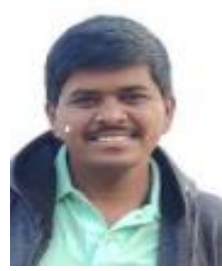

Rustum Dhalait is a full-time Ph.D. research scholar in the WCE, Sangli. His research work focuses on the areas of Heat Transfer, Fluid Dynamics, Refrigeration and Air Conditioning waste heat recovery, and organic rankine cycle. He worked as a Lecturer in GCOE, Karad for one year. He has published 05 research papers in various standard journals and conferences on the international and national levels. Email: rustamdhalait1694@gmail.com

\begin{tabular}{|c|c|c|}
\hline S.No. & Abbreviation & Description \\
\hline 1 & ANFIS & $\begin{array}{l}\text { Artificial Neuro Fuzzy Inference } \\
\text { System }\end{array}$ \\
\hline 2 & ANN & Artificial Neural Network \\
\hline 3 & ANSYS & Analysis of Systems \\
\hline 4 & CHX & Cold End Heat Exchanger \\
\hline 5 & CFD & Computational Fluid Dynamics \\
\hline 6 & COP & Coefficient of Performance \\
\hline 7 & $\mathrm{CPU}$ & Central Processing Unit \\
\hline 8 & DI & Double Inlet \\
\hline 9 & DIPTC & Double Inlet Pulse Tube Cryocooler \\
\hline 10 & DITSIPTC & $\begin{array}{l}\text { Double Inlet Two-Stage Inertance } \\
\text { Pulse Tube Cryocooler }\end{array}$ \\
\hline 11 & DITSPTC & $\begin{array}{l}\text { Double Inlet Two-Stage Pulse Tube } \\
\text { Cryocooler }\end{array}$ \\
\hline 12 & FLUENT & $\begin{array}{l}\text { Fluid, Liquid, Smooth and } \\
\text { Unconstrained in Movement }\end{array}$ \\
\hline 13 & $\begin{array}{l}\text { HHX1 and } \\
\text { HHX2 }\end{array}$ & Hot End Heat Exchangers \\
\hline 14 & $\mathrm{HX}$ & Hot Heat Exchanger \\
\hline 15 & IPTC & Inertance Tube Pulse Tube Cryocooler \\
\hline 16 & OPTC & Orifice Pulse Tube Cryocooler \\
\hline 17 & PSO & Particle Swarm Optimization \\
\hline 18 & PTC & Pulse Tube Cryocooler \\
\hline 19 & RAM & Random Access Memory \\
\hline 20 & SPC & Stirling/Pulse Tube Hybrid Cryocooler \\
\hline 21 & TSIPTC & $\begin{array}{l}\text { Two-Stage Inertance Pulse Tube } \\
\text { Cryocooler }\end{array}$ \\
\hline 22 & TSPTC & Two-Stage Pulse Tube Cryocooler \\
\hline 23 & UDF & User Defined Function \\
\hline
\end{tabular}

\begin{tabular}{clcl}
\hline \multicolumn{2}{l}{ Nomenclature } & & \\
\hline $\mathrm{C}_{2}$ & Inertial resistance factor & \multicolumn{2}{c}{ Greek symbols } \\
\hline $\mathrm{E}$ & Total energy of the fluid & $\alpha$ & Permeability \\
\hline $\mathrm{E}_{\mathrm{f}}$ & Fluid energy & $\varepsilon$ & Void number \\
\hline $\mathrm{E}_{\mathrm{s}}$ & Solid medium energy & $\vec{v}$ & Velocity \\
\hline $\mathrm{k}_{\mathrm{eff}}$ & Effective thermal conductivity & $\overline{\bar{\tau}}$ & Stress tensor \\
\hline $\mathrm{P}$ & Static pressure & $\rho$ & Fluid density \\
\hline $\mathrm{T}$ & Temperature & & \\
\hline
\end{tabular}

